\title{
COMMENTARY
}

\section{Prognostic indicators in patients presenting with acute cardiogenic pulmonary edema treated with CPAP: it's not the acid that matters, it's back to basics}

\author{
Dominik Schlosshan*1 and Mark Elliott ${ }^{2}$ \\ See related research by Aliberti et al., http://ccforum.com/content/14/6/R196
}

\begin{abstract}
Several prognostic markers have been identified for patients admitted with acute cardiogenic pulmonary edema. Most of the markers are based on clinical risk scores. Unlike hypercapnic respiratory failure, acidosis is not an adverse predictor in these patients. Hemodynamic variables that assess pathophysiological mechanisms may be more helpful to guide appropriate management.
\end{abstract}

In this issue of Critical Care, Aliberti and colleagues [1] examine the question of whether acidemia predicts outcome in patients admitted with acute cardiogenic pulmonary edema (ACPE) and treated with continuous positive airway pressure (CPAP). The authors performed a retrospective observational study in a large cohort of patients admitted to the emergency department with ACPE and treated with CPAP. The authors compared treatment failure, defined as a switch to bi-level or invasive ventilation or in-hospital mortality, in two matched groups of patients with and without acidemia on admission. The main conclusion was that neither admission acidemia nor type was an adverse prognostic marker.

Acute heart failure syndromes (AHFSs) are the most common reason for hospital admission in patients older than 65 years, over $50 \%$ of whom present with ACPE [2], and up to $10 \%$ of patients with ACPE will not survive

*Correspondence: dschlo1038@aol.com

'Department of Cardiology, Yorkshire Heart Centre, Leeds General Infirmary, Great George Street, Leeds, LS1 3EX, UK

Full list of author information is available at the end of the article their admission [3]. A number of prognostic factors have been identified: age, systolic blood pressure (SBP), brain natriuretic peptide or troponin rise, hyponatremia, renal dysfunction, previous ischemic heart disease, ejection fraction, and function at discharge. However, most of these variables have been used across the whole spectrum of AHFSs and relate to longer-term outcome [4,5]. Focusing on ACPE only, the $3 \mathrm{CPO}$ Trialists identified patients at immediate risk of death and in need of intervention on presentation; a simple score based on age, SBP, and the ability to obey commands predicted early mortality [6].

In acute exacerbations of chronic obstructive pulmonary disease, acidosis is a strong predictor of adverse outcome [7]. Why does it not have similar prognostic implications in ACPE? Acidosis in hypercapnic respiratory failure is a direct reflection of organ dysfunction, in particular the failure of the lungs to ventilate the alveoli adequately. In contrast, in ACPE, acidosis is only an indirect consequence of cardiac dysfunction caused by a combination of factors, including edema-impaired gas exchange and tissue hypoperfusion. The absence of acidosis is unusual in patients with ACPE [1]. It is therefore not surprising that acidosis is a poor discriminator of outcome. More direct indicators of cardiac function, such as cardiac power output (CPO), which is derived from the product of cardiac output and mean arterial blood pressure, have been shown to be powerful prognostic indicators in patients with AHFS, chronic heart failure (CHF), or cardiogenic shock [8-10].

Clinical risk scores, a product of statistical modeling, are a popular tool to identify prognostic markers. However, most do not pass the acid test of clinical utility, and this is evidence that a change in risk score correlates with changes in patient outcome. Furthermore, most risk scores do not provide any information on underlying pathophysiology. 
Differentiating the pathophysiological processes underpinning the different AHFSs to provide appropriate and rational treatment is an alternative approach to riskstratify patients with ACPE. Cotter and colleagues [11] suggested four major clinical AHFSs: (a) pulmonary edema, (b) cardiogenic shock, (c) hypertensive (HTN) crisis, and (d) exacerbated systolic CHF. By plotting CPO as a marker of cardiac contractility against systemic vascular resistance (SVR), the authors demonstrated that $95 \%$ of patients could be categorized accurately into one of these syndromes [12]. Understanding the pathophysiological mechanisms is key to management; for example, patients with cardiogenic shock and those with pulmonary edema demonstrate a similar presentation with pulmonary congestion, clammy extremities, low cardiac output, and high wedge pressure. However, the pathophysiologies are very different and the treatments are almost opposite. The former is characterized by low CPO and low SVR that requires inotropic support and occasionally peripheral vasoconstrictors, and the latter is characterized by extreme neurohormonal activation with higher values of CPO and very high SVR, necessitating aggressive peripheral vasodilation. According to this model, exacerbated systolic CHF, HTN crisis, and ACPE may be viewed as a continuum of progressive neurohormonal activation leading to an increase in SVR with progressive recruitment of cardiac power reserve [8]. The objective of treatment is then to optimize the SVR and thus the cardiac performance can be moved toward more optimal loading conditions to effect greater power output [13]. The need for invasive hemodynamic monitoring is a limitation, but the advent of non-invasive tools could improve diagnosis, risk stratification, and management of patients with AHFS.

The etiology of heart failure and the cardiac rhythm influence the acute cardiac response to CPAP. In patients with dilated cardiomyopathy, CPAPs lead to a reduction in cardiac volumes, whereas in ischemic cardiomyopathy, there were small increases [14]. Similarly, atrial fibrillation resulted in a fall in cardiac index but there was a small rise in sinus rhythm [15].

CPAP, with its unique combination of respiratory and hemodynamic effects, will remain a cornerstone of the symptomatic treatment of ACPE. Future management should look beyond clinical risk scores to an understanding of etiology and pathophysiology in each patient to provide optimal treatment for this deadly condition.

\section{Abbreviations}

ACPE, acute cardiogenic pulmonary edema; AHFS, acute heart failure syndrome; $\mathrm{CHF}$, chronic heart failure; CPAP, continuous positive airway pressure; CPO, cardiac power output; HTN, hypertensive; SBP, systolic blood pressure; SVR, systemic vascular resistance.
Competing interests

The authors declare that they have no competing interests.

\section{Author details}

'Department of Cardiology, Yorkshire Heart Centre, Leeds General Infirmary, Great George Street, Leeds, LS1 3EX, UK. ²Department of Respiratory Medicine, St James's University Hospital, Beckett Street, Leeds, LS9 7TF, UK.

Published: 3 December 2010

\section{References}

1. Aliberti S, Piffer F, Brambilla AM, Bignamini AA, Rosti VD, Maraffi T, Monzani V, Cosentini R: Acidemia does not affect outcomes of patients with acute cardiogenic pulmonary edema treated with continuous positive airway pressure. Crit Care 2010, 14:R196.

2. Gheorghiade M, Zannad F, Sopko G, Klein L, Pina IL, Konstam MA, Massie BM, Roland E, Targum S, Collins SP, Filippatos G, Tavazzi L; International Working Group on Acute Heart Failure Syndromes: Acute heart failure syndromes: current state and framework for future research. Circulation 2005, 112:3958-3968.

3. Kaluski E, Kobrin I, Zimlichman R, Marmor A, Krakov O, Milo O, Frey A, Kaplan S, Krakover R, Caspi A, Vered Z, Cotter G: RITZ-5: randomized intravenous TeZosentan (an endothelin-A/B antagonist) for the treatment of pulmonary edema: a prospective, multicenter, double-blind, placebocontrolled study. J Am Coll Cardio/ 2003, 41:204-210.

4. Gheorghiade M, Pang PS: Acute heart failure syndromes. J Am Coll Cardiol 2009, 53:557-573.

5. Gheorghiade M, Abraham WT, Albert NM, Greenberg BH, O'Connor CM, She L, Stough WG, Yancy CW, Young JB, Fonarow GC; OPTIMIZE-HF Investigators and Coordinators: Systolic blood pressure at admission, clinical characteristics, and outcomes in patients hospitalized with acute heart failure. JAMA 2006, 296:2217-2226.

6. Gray A, Goodacre S, Nicholl J, Masson M, Sampson F, Elliott M, Crane S, Newby DE; 3CPO Trialists: The development of a simple risk score to predict early outcome in severe acute acidotic cardiogenic pulmonary edema: the 3CPO score. Circ Heart Fail 2010, 3:111-117.

7. Plant PK, Owen JL, Elliott MW: Non-invasive ventilation in acute exacerbations of chronic obstructive pulmonary disease: long term survival and predictors of in-hospital outcome. Thorax 2001, 56:708-712.

8. Tan LB: Cardiac pumping capability and prognosis in heart failure. Lancet 1986, ii:1360-1363.

9. Cotter G, Williams SG, Vered Z, Tan LB: Role of cardiac power in heart failure. Curr Opin Cardiol 2003, 18:215-222.

10. Williams SG, Cooke GA, Wright DJ, Parsons WJ, Riley RL, Marshall P, Tan LB: Peak exercise cardiac power output; a direct indicator of cardiac function strongly predictive of prognosis in chronic heart failure. Eur Heart J 2001, 22:1496-1503.

11. Cotter G, Moshkovitz Y, Milovanov O, Salah A, Blatt A, Krakover R, Vered Z, Kaluski E: Acute heart failure: a novel approach to its pathogenesis and treatment. Eur J Heart Fail 2002, 4:227-234.

12. Cotter G, Moshkovitz Y, Kaluski E, Milo O, Nobikov Y, Schneeweiss A, Krakover $R$, Vered $Z$ : The role of cardiac power and systemic vascular resistance in the pathophysiology and diagnosis of patients with acute congestive heart failure. Eur J Heart Fail 2003, 5:443-451.

13. Tan LB, Williams SG, Wright DJ: Ventriculo-arterial function curves - a new dimension in characterising acute heart failure. Eur J Heart Fail 2003, 5:407-410.

14. Mehta S, Liu PP, Fitzgerald FS, Allidina YK, Douglas BT: Effects of continuous positive airway pressure on cardiac volumes in patients with ischemic and dilated cardiomyopathy. Am J Respir Crit Care Med 2000, 161:128-134.

15. Kiely JL, Deegan P, Buckley A, Shiels P, Maurer B, McNicholas WT: Efficacy of nasal continuous positive airway pressure therapy in chronic heart failure: importance of underlying cardiac rhythm. Thorax 1998, 53:957-962.

doi:10.1186/cc9325

Cite this article as: Schlosshan D, Elliott M: Prognostic indicators in patients presenting with acute cardiogenic pulmonary edema treated with CPAP: it's not the acid that matters, it's back to basics. Critical Care 2010, 14:1009. 